\title{
Novel Method for the Extraction of Cocaine from Oral Fluid by Means of Disposable Pipette Modified with Restricted Access Material
}

\author{
Ludmyla S. Tavares, ${ }^{a}$ Ricardo A. Bernardo, ${ }^{a}$ Anselmo E. de Oliveira, ${ }^{b}$ Boniek G. Vaz ${ }^{\oplus a}$ \\ and Andrea R. Chaves ${ }^{\circledR} *, a$
}

${ }^{a}$ Laboratório de Cromatografia e Espectrometria de Massas, Instituto de Química,
Universidade Federal de Goiás, 74690-900 Goiânia-GO, Brazil

${ }^{b}$ Laboratório de Química Teórica e Computacional, Instituto de Química, Universidade Federal de Goiás, 74690-900 Goiânia-GO, Brazil

\begin{abstract}
This study proposes a new, efficient, and selective method for the analysis of cocaine in oral fluid. For this purpose, an extractive phase with restricted access materials (RAM) capable of extract and pre-concentrate low molecular weight analytes and simultaneously exclude macromolecules was developed for disposable pipette extraction (DPX) followed by liquid chromatography coupled to mass spectrometry (LC-MS) analyses. The proposed method was optimized using a $2^{4}$ factorial

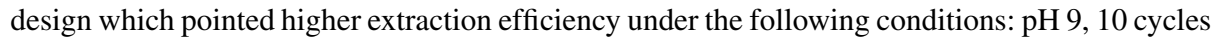
of extraction (aspirate/dispense), 3 cycles of desorption (aspirate/dispense) and acetonitrile as desorption solvent. The DPX-RAM/LC-MS method showed linearity range from 10 to $100 \mathrm{ng} \mathrm{mL}^{-1}$ with determination coefficient $\left(\mathrm{R}^{2}\right)=0.999$, accuracy values ranged from -0.9 to $4.3 \%$, precision values ranged from 1.7 to $9.1 \%$ and recovery values ranged from 97.9 to $101.1 \%$. The benefits of this method are that it can be performed in few minutes and that the analytical performances, including the limit of detection $\left(3.13 \mathrm{ng} \mathrm{mL}^{-1}\right)$, limit of quantitation $\left(10 \mathrm{ng} \mathrm{mL}^{-1}\right)$ and linear range were found to be in agreement with other methods used for similar analysis.
\end{abstract}

Keywords: cocaine, restricted access materials, disposable pipette extraction, desorption, validation

\section{Introduction}

Cocaine is an alkaloid derived from the Erythroxylum coca plant that grows abundantly in the Andes region of South America. ${ }^{1}$ It can be mainly found in the cocaine hydrochloride form, a white crystalline powder, which is introduced to the human body by inhalation, ingestion or directly injected into the blood stream. Cocaine effects in the human body may include topical local anesthetics, ability to block reuptake of the neurotransmitters, such as dopamine, epinephrine and serotonin. ${ }^{2}$ Cocaine also acts as stimulant drug, being widely used for truck-drivers during long travels. ${ }^{3}$

Many countries in South America, and worldwide, have passed legislation dictating that individuals must provide oral fluid, blood, hair, or nail samples to renew driver's licenses, which necessitate the development of reliable methods, with high throughput, for the analysis of drugs of abuse, and their analytes, in these biological matrices. ${ }^{4,5}$

*e-mail: andrea_chaves@ufg.br
Among the conventional biological matrices, urine is the most commonly used matrix for the analysis and identification of drugs and toxic substances due to the high concentration of analytes present in this matrix. In addition to analyzing the parent compound, it is necessary to detect various metabolic products that are generated as the body processes these compounds before elimination in urine. ${ }^{6}$ An alternative matrix is oral fluid, which has high concentration of analytes in their original form before they can be metabolized. ${ }^{7}$ Other benefits of using oral fluid as a biological matrix are that it is an easy and noninvasive matrix to collect. Thus, the collection can be performed in remote locations where there are no medical facilities available. ${ }^{8}$

Samples originating from biological matrices are complex due to the presence of endogenous compounds, such as proteins, ${ }^{9}$ hormones, ${ }^{10}$ lipids,,${ }^{11}$ and metabolites, ${ }^{12}$ and a clean-up and pre-concentration step must be performed before injecting in chromatographic systems. ${ }^{13}$ Historically, liquid-liquid extraction has been used for the 
isolation of drugs from biological samples. More recently, many of these liquid-liquid methods have been adapted or modified to include solid-phase extractions (SPE). ${ }^{14} \mathrm{SPE}$ has proven to be useful for sample preparation in oral fluid drug testing because of its high recovery rates and ease of use. ${ }^{15-17}$ In general, SPE is faster, more efficient, and more selective, and it uses less solvent than liquid-liquid extraction methods. ${ }^{14,18}$

Disposable pipette extraction (DPX) is a miniaturized technique based on SPE. DPX uses a small amount of adsorbent (30 mg) which is placed inside of a micropipette tip containing a filter on the bottom and it may also contain a filter at the top. ${ }^{19-22}$ Although DPX is derived from SPE, the efficiency of extraction is based on the time of sorption equilibrium between the sample solution and the adsorbent phase, consequently, this process is not dependent on the sample flow rate. Besides that, the miniaturized design of DPX consumes smaller volumes of solvents compared to traditional SPE. ${ }^{22,23}$

There are a lot of commercially available phases that can be used in DPX, they are all based on chromatographic media, such as C18 and C8 microparticles, hydrophobic or ion exchange phases. ${ }^{24-26}$ On the other hand, there are a lot of advantages of manufacturing new phases including easy preparation and control of permeability and enhancement of the selectivity. ${ }^{27}$

Restricted access materials (RAM) are a class of biocompatible compounds that were first reported by Desilets et $a l .^{28}$ in 1991. In general, RAM materials are derived from silica, being widely used with chromatography techniques for the separation of compounds with lower molecular weight from complex matrices. ${ }^{19} \mathrm{~A}$ macromolecule such as protein, is immobilized onto the silica surface, and during the extraction process, this immobilized protein acts as a barrier to endogenous compounds. Furthermore, the analytes are sufficiently small to permeate this barrier and interact with the silica surface (Figure 1). The immobilized protein present in the surface of hydrophobic RAM combines the extraction mechanism

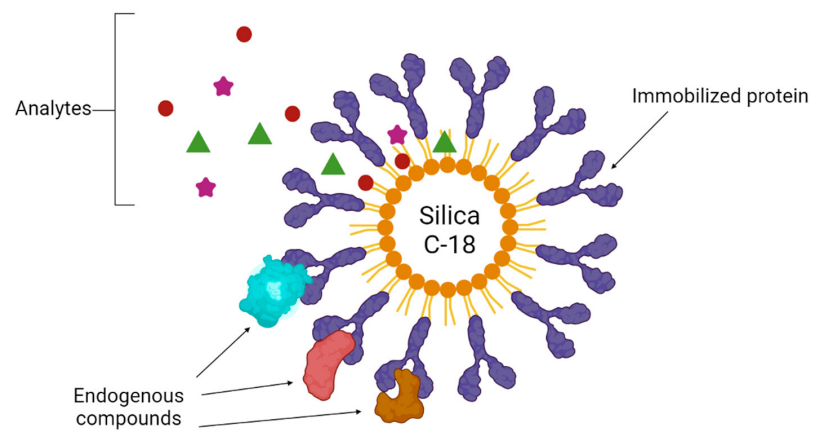

Figure 1. Extraction process of a restricted access material based on protein immobilized onto a silica $\mathrm{C}-18$ surface. of barrier exclusion and partition. The macromolecules are excluded and interact only with the external surface of support particles, and the analytes interact with the hydrophobic interior modified with protein. ${ }^{28,29}$

In the present study, a DPX-RAM/liquid chromatography coupled to mass spectrometry (LC-MS) method was developed and applied for the analysis of cocaine in oral fluid. In addition, this work focused on developing the sorbent and optimizing the extraction conditions using a factorial design.

\section{Experimental}

\section{Chemicals and reagents}

Methanol and acetonitrile high-performance liquid chromatography (HPLC) grade were acquired from J.T. Baker (Phillipsburg, USA); SPE C-18 cartridge was acquired from Supelco (São Paulo, Brazil). Sodium phosphate monobasic, sodium azide, and ammonium acetate were acquired from Mallinckrodt (Mexico city, Mexico). Benzophenone, potassium chloride, and glutaraldehyde $25 \%$ were acquired from Vetec (Rio de Janeiro, Brazil). Methacrylic acid, ethylene dimethacrylate, formic acid, potassium hydroxide, and bovine serum albumin (BSA) were acquired from Sigma-Aldrich (Taufkirchen, Germany). Hydroxyethyl cellulose was acquired from Polytechno Indústrias Químicas Ltda. (São Paulo, Brazil). Calcium chloride dihydrate and magnesium chloride hexahydrate were acquired from Labsynth (Diadema, Brazil). Acetone P.A. grade was acquired from Scharlau (Sentmenat, Spain). Cellulose membrane (diameter: $47 \mathrm{~mm}$, and pore size: $0.45 \mu \mathrm{m}$ ) was acquired from Agilent Technologies (Frankfurt, Germany). The water employed in this study was ultrapurified in a system Gehaka MS-2000 WFi (São Paulo, Brazil).

The cocaine standard employed for the method optimization was kindly donated by the Polícia Civil do Estado de Goiás. In the validation step, a cocaine standard suitable for LC and gas chromatography (GC) analysis was acquired from Sigma-Aldrich (Round Rock, Texas, USA) and kindly donated by Prof Wanderson Romão from the Chemistry Department of Universidade Federal do Espírito Santo.

\section{RAM-BSA phase synthesis}

The restrict access material adsorbent modified with bovine serum albumin (RAM-BSA) was prepared as described by Chaves et al. ${ }^{19}$ An SPE cartridge containing $\mathrm{C}-18$ silica was positioned in a manifold and conditioning with $3 \mathrm{~mL}$ of a $0.05 \mathrm{~mol} \mathrm{~L}^{-1}$ phosphate buffer solution (PBS) 
with $\mathrm{pH}$ 6. Then, the BSA was immobilized in the phase by treating it with $10 \mathrm{~mL}$ of a $2 \mathrm{mg} \mathrm{mL}^{-1}$ BSA solution for $15 \mathrm{~min}$, and then, the cartridge was washed with $5 \mathrm{~mL}$ of ultrapurified water.

Thereafter, the cartridge was immersed with $5 \mathrm{~mL}$ of glutaraldehyde $25 \%$ and left to rest for $5 \mathrm{~h}$. After that, $5 \mathrm{~mL}$ of a $1.0 \mathrm{mg} \mathrm{mL}^{-1}$ sodium azide solution was eluted through the cartridge until $\mathrm{pH} 10$ was reached. The cartridge remained in rest for $2 \mathrm{~h}$. Finally, the cartridge was washed with ultrapurified water for $1 \mathrm{~h}$ and stored in PBS $0.05 \mathrm{~mol} \mathrm{~L}^{-1}$ with pH 6 at the temperature of $4{ }^{\circ} \mathrm{C}$ until use. The workflow for RAM-BSA synthesis is presented in Figure 2.

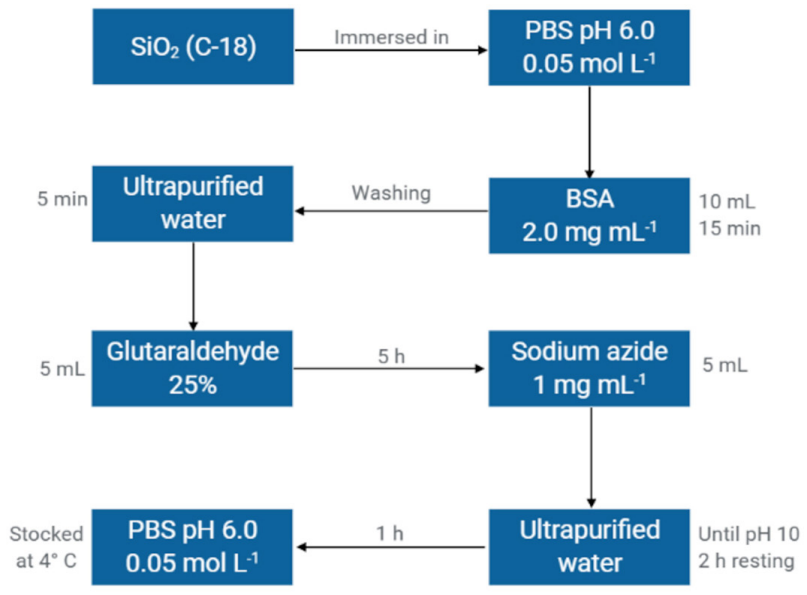

Figure 2. Schematic representation of RAM-BSA synthesis.

\section{DPX tip preparation}

In order to prepare the DPX tips, $10 \mathrm{mg}$ of glass wool was set in the lower end of a $1 \mathrm{~mL}$ pipette tip. Then, $30 \mathrm{mg}$ of RAM-BSA phase was placed inside the tip and washed with $2 \mathrm{~mL}$ of ultrapurified water. The DPX tips were prepared immediately before each experiment, and they were used for 10 cycles of extraction/desorption without extraction efficiency reduced (Figure 3). Between each extraction, the tip was washed twice with $1 \mathrm{~mL}$ of acetonitrile and twice with ultrapurified water.

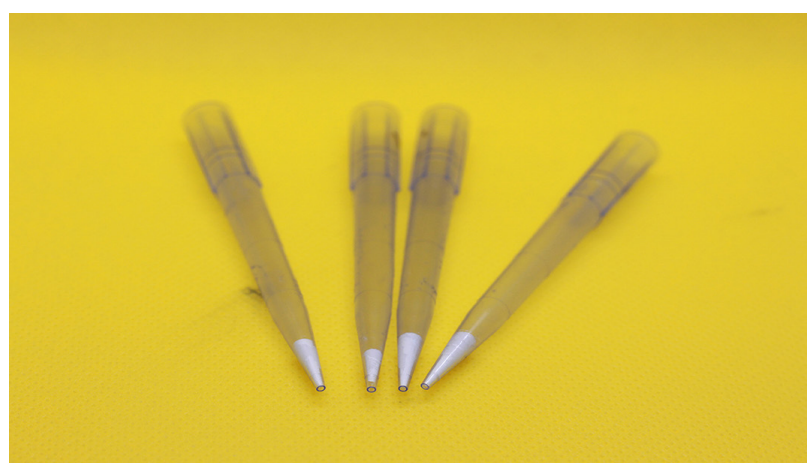

Figure 3. Pipette tips with RAM phase used in the present study.
Oral fluid and synthetic saliva samples

Synthetic saliva was used during the optimization of the parameters of the DPX-RAM/LC-MS method and it was prepared by adaptation of the protocol presented by Alshali et al.$^{30}$ Briefly, $0.25 \mathrm{~g}$ of hydroxyethyl cellulose was dissolved in $400 \mathrm{~mL}$ of ultrapurified water. The solution was left under magnetic stirring for $24 \mathrm{~h}$ in order to achieve total dissolution. Then, potassium chloride $\left(0.625 \mathrm{~g} \mathrm{~L}^{-1}\right)$, calcium chloride dihydrate $\left(0.166 \mathrm{~g} \mathrm{~L}^{-1}\right)$, potassium phosphate monobasic $\left(0.326 \mathrm{~g} \mathrm{~L}^{-1}\right)$, magnesium chloride hexahydrate $\left(0.059 \mathrm{~g} \mathrm{~L}^{-1}\right)$ and bovine serum albumin $\left(0.00235 \mathrm{~g} \mathrm{~L}^{-1}\right)$ were added to the solution. After the dissolution of all the reagents, the $\mathrm{pH}$ was adjusted to 6.75 with potassium hydroxide and the volume was completed to $500 \mathrm{~mL}$.

For the validation of the method, a pool of oral fluid collected from 10 nonuser volunteers was used. The authentic oral fluid samples were diluted 5 times with ultrapurified water and spiked with cocaine. The samples were collected following the ethics principles and had been approved by the Universidade Federal de Goiás ethical committee (Comitê de Ética em Pesquisa (CEP) 056/13). No real samples from drug users were evaluated, once the objective of this study is to present the applicability of the RAM extractive phase for DPX sample preparation steps.

\section{Factorial design}

Aiming to optimize the extraction conditions of DPX-RAM and determine the most significant parameters, a factorial design $2^{\mathrm{k}}$ was used, where $\mathrm{k}=4$. The variables to be considered were coded as follows: $\mathrm{a}=\mathrm{pH}, \mathrm{b}=$ extraction cycles, $\mathrm{c}=$ desorption cycles and $\mathrm{d}=$ desorption solvent. The levels of each variable are presented in Table 1.

Table 1. Parameters, variables, and levels used in the factorial design $2^{4}$

\begin{tabular}{lccc}
\hline Parameter & Variable & Lower level & Higher level \\
\hline $\mathrm{a}$ & $\mathrm{pH}$ & 4 & 9 \\
$\mathrm{~b}$ & extraction cycles & 3 & 10 \\
$\mathrm{c}$ & desorption cycles & 3 & 10 \\
$\mathrm{~d}$ & solvent & acetonitrile & methanol \\
\hline
\end{tabular}

Following the factorial design, sixteen randomized extractions were performed in duplicate. The samples were prepared in $500 \mu \mathrm{L}$ of synthetic saliva spiked with cocaine at the concentration of $100 \mathrm{ng} \mathrm{mL}^{-1}$ and $500 \mu \mathrm{L}$ of buffer solution (phosphate $0.05 \mathrm{~mol} \mathrm{~L}^{-1} \mathrm{pH} 9$ or acetate $0.05 \mathrm{~mol} \mathrm{~L}^{-1} \mathrm{pH} 4$ ). $250 \mu \mathrm{L}$ of sample was aspirated/ dispensed 3 or 10 times in the extraction cycle using the same sample vial, then $500 \mu \mathrm{L}$ of desorption solvent 
(methanol or acetonitrile) were aspirated/dispensed 3 or 10 times in a vial flask. Moreover, the extractions were performed using 10 cycles of extraction (aspirate/dispense), acetonitrile as desorption solvent in 3 cycles of desorption. It is necessary to highlight that RAM sorbents usually recommend the use between $\mathrm{pH} 5$ to 9, once RAM sorbent did not exhibit good protein exclusion near to isoelectric point. For factorial design, an extreme condition was used.

\section{Chromatographic conditions}

Analysis was performed in a Shimadzu LC-20A high performance liquid chromatography with a UV-Vis Shimadzu SPD-20A detector set at the wavelength of $235 \mathrm{~nm}$. The separations were performed using a Phenomenex Luna C-18 $(5 \mu \mathrm{m}, 150 \times 4.6 \mathrm{~mm})$ column. The mobile phase consisted of A: $10 \mathrm{mM}$ of ammonium acetate in water with $0.01 \%$ formic acid and B: acetonitrile, in isocratic mode 25:75 v/v, respectively, at a flow rate of $0.3 \mathrm{~mL} \mathrm{~min}^{-1}$.

\section{Experimental conditions of mass spectrometer}

The mass spectrometer used in the DPX-RAM/LC-MS method was a micrOTOF-Q III, fabricated by Bruker (Billerica, USA). The experiments were performed in positive mode, at a flow rate of $5 \mathrm{~L} \mathrm{~min}^{-1}$ of drying gas, electrospray ionization (ESI) source temperature of $280^{\circ} \mathrm{C}$, nebulizer pressure of 0.5 bar, the capillary voltage of $2800 \mathrm{~V}$ and the mode of operation was MS/MS.

\section{Bradford test}

In order to evaluate the efficiency of the RAM-BSA phase in excluding proteins and endogenous compounds, oral fluid samples were submitted to a Bradford test before and after extraction. This test was performed in a UV-Vis Ultrospec 2000 spectrometer, fabricated by Pharmacia Biotech.

Concisely, the method developed by Bradford ${ }^{31}$ involves the bounding of reagent Coomassie Brilliant Blue G-250 to the proteins present in the sample. The bounding of the Bradford's reagent to proteins promotes a change in its maximum absorption, changing from 465 to $595 \mathrm{~nm}$, and this change is monitored by UV-Vis spectrophotometry. The protein quantification is performed through an analytical curve, using different human albumin solution concentration as a protein source.

\section{Analytical essays}

In the present study, the analytical validation parameters were evaluated as described by Agência Nacional de
Vigilância Sanitária (ANVISA) in resolution RDC No. 166 of July $24^{\text {th }}, 2017 . .^{32}$ Thus, accuracy, precision, recovery, linearity, limits of detection and quantitation, and matrix effect were evaluated. In this study, no internal standard was used, because the chromatographer was coupled to a high-resolution MS system, and the DataAnalysis software version 5.0 with peak attribution error less than $3 \mathrm{ppm}$.

\section{Results and Discussion}

\section{RAM phase synthesis}

In the synthesis of the RAM phase, the $0.05 \mathrm{~mol} \mathrm{~L}^{-1}$ phosphate buffer solution $\mathrm{pH} 6$ was employed to ensure that the BSA protein was not denatured. The solution of glutaraldehyde $25 \%$ was used to assist the stabilization of the immobilized protein, then, the sodium azide solution was added to reduce residual glutaraldehyde clusters and prevent further reactions.

After the synthesis, the RAM-BSA phase was kept in PBS solution $0.05 \mathrm{~mol} \mathrm{~L}^{-1} \mathrm{pH} 6$ in refrigerator to ensure immobilized protein integrity. ${ }^{33}$

\section{Protein exclusion test}

Bradford tests are commonly used in the quantitation of total proteins ${ }^{31}$ and was used in this study to evaluate the capability of the developed RAM-BSA phase to exclude proteins. The method developed by Bradford involves the bond of the reagent Coomassie Brilliant Blue G-250 to the proteins present in the sample. The bond of the dye to the protein causes a change in the maximum absorption of the dye from 465 to $595 \mathrm{~nm}$ and this change in absorption is monitored by the UV-Vis spectrometer. The protein quantitation is performed using an analytical curve built with human serum albumin standard solution. The developed analytical curve is presented below on equation 1 :

$\mathrm{y}=\left(\frac{\mathrm{X}-0.0809}{0.0423}\right) \times 10 \mu \mathrm{g} \mathrm{mL} \mathrm{H}^{-1}$

where, $\mathrm{y}$ is the concentration of proteins present in the sample, and $\mathrm{X}$ is the measurement of the spectrometer.

In this test, a sample of authentic oral fluid was prepared by diluting it 5-fold according to the developed method and divided in two aliquots, the first one was not submitted to any extraction. The second one was extracted using the DPX-RAM protocol described in this paper and then the oral fluid sample that usually is discarded after the extraction was collected to be analyzed for its protein 
content. Table 2 shows that the concentration of proteins present in the sample before and after the extraction are very close, proving that the RAM-BSA is in fact, excluding the endogenous compounds present in the sample.

Table 2. Bradford test to oral fluid before and after the extraction process

\begin{tabular}{lcc}
\hline Sample & $\begin{array}{c}\text { Measurement of } \\
\text { spectrometer }\end{array}$ & $\begin{array}{c}\text { Concentration / } \\
\left(\mu \mathrm{gLL}^{-1}\right)\end{array}$ \\
\hline Extracted oral fluid & 0.111 & 7.115 \\
Oral fluid without extraction & 0.112 & 7.352 \\
\hline
\end{tabular}

\section{Chromatographic conditions optimization}

In order to perform the analytical validation of the DPXRAM/LC-MS method, the chromatographic conditions were evaluated employing two different columns, three mobile phases, and two wavelengths, as shown in Table 3. The evaluated conditions were selected according to the literature. ${ }^{34-38}$

Table 3. Chromatographic conditions evaluated in the method's optimization

\begin{tabular}{lcc}
\hline Mobile phase & Column & Wavelength / nm \\
\hline $\begin{array}{l}\text { Methanol and water } \\
0.01 \% \text { formic acid }\end{array}$ & $\begin{array}{c}\text { Agilent XDB C18 } \\
(70: 30 \mathrm{v} / \mathrm{v})\end{array}$ & 235 \\
\hline $\begin{array}{l}\text { Methanol and } \\
\text { ammonium acetate }\end{array}$ & $\begin{array}{c}\text { Phenomenex Luna C18 } \\
10 \mathrm{mM} 0.01 \% \text { formic }\end{array}$ & 200 \\
acid $(70: 30 \mathrm{v} / \mathrm{v})$ & $250 \times 4.6 \mathrm{~mm})$ & \\
\hline $\begin{array}{l}\text { Acetonitrile and } \\
\text { ammonium acetate }\end{array}$ & Phenomenex Luna C18 & \\
$\begin{array}{l}10 \mathrm{mM} 0.01 \% \text { acid } \\
\text { formic }(75: 25 \mathrm{v} / \mathrm{v})\end{array}$ & $(5 \mu \mathrm{m}, 150 \times 4.6 \mathrm{~mm})$ & 235 \\
\hline
\end{tabular}

The higher chromatographic efficiency was obtained with a Phenomenex Luna C-18 column, acetonitrile:

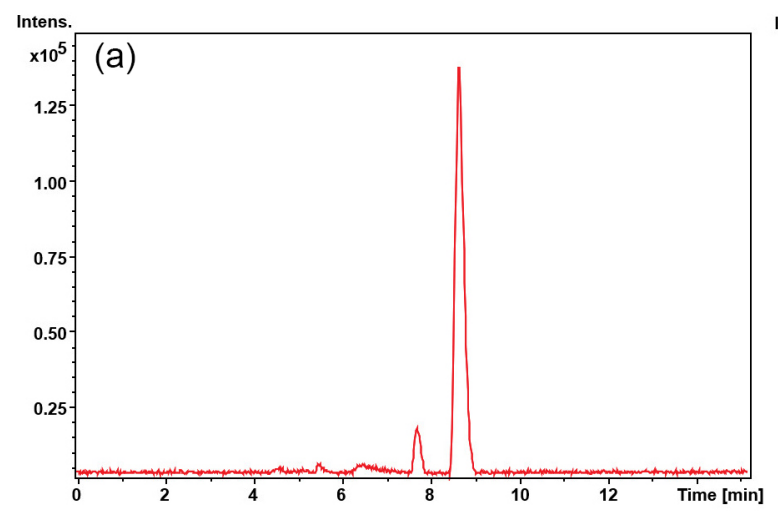

$10 \mathrm{mmol} \mathrm{L}-1$ ammonium acetate $0.01 \%$ formic acid $(75: 25, \mathrm{v} / \mathrm{v})$ as mobile phase and wavelength of $235 \mathrm{~nm}$. In this optimized condition, the retention time of cocaine standard solution at $100 \mathrm{ng} \mathrm{mL}^{-1}$ was $8.7 \mathrm{~min}$. The experimental conditions of the mass spectrometer were adjusted to suit the flow rate and chromatographic conditions. The total ion chromatogram and the respective mass spectrum are presented in Figure 4.

\section{Factorial design}

For the optimization of the extraction using the DPX-RAM protocol a factorial design $2^{\mathrm{k}}, \mathrm{k}=4$ was employed, meaning that 4 variables were evaluated in the planning of experiments. The oral fluid samples spiked with cocaine were submitted to extraction with the DPX-RAM in duplicate in the 16 experimental conditions, and the obtained extracts were analyzed by LC-MS. Table 4 presents the performed experiments and the results in each essay in the factorial design $2^{4}$, the responses correspond to the absolute intensity of the cocaine peak in the mass spectrum. The data were analyzed with the aid of Design-Expert software. ${ }^{39}$

In the semi-normal distribution graph (Figure 5), the most significant effects are those that move further away from the linear model followed by the other effects. Therefore, it is observed that the most significant effects are caused by the extraction cycle at the high level and by the solvent at the low level.

The Pareto diagram was used for a more precise analysis and it is shown in Figure 6. In this bar chart, the occurrence frequencies are ordered, from highest to lowest, allowing the best visualization of the most significant effects. There is a limit line, calculated by the $t$-Student test. The variables with the highest significance in the experiment should be above the limit line.

According to the Pareto diagram, the most significant effects are the same as those found by the graph of semi-

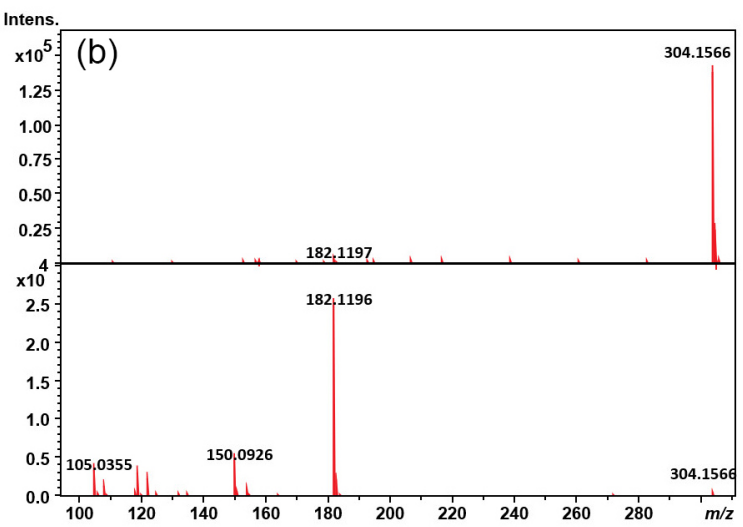

Figure 4. (a) Total ion chromatogram; (b) mass spectrum of the retention time $8.7 \mathrm{~min}$ on the top and its MS/MS spectrum on the bottom acquired in the optimized conditions of analysis. 
Table 4. Absolute intensity of the cocaine peak in the MS spectrum for each essay in the factorial design $2^{4}$. High (+) and low (-) levels according to Table 1

\begin{tabular}{|c|c|c|c|c|c|c|}
\hline Experiment & $\mathrm{pH}$ & Extraction cycle & Desorption cycle & Solvent & $\begin{array}{l}\text { Absolute intensity of } \\
\text { response/peak } 1\end{array}$ & $\begin{array}{l}\text { olute intensity of } \\
\text { response } 2\end{array}$ \\
\hline 1 & - & - & - & - & 19448 & 13742 \\
\hline 2 & + & - & - & - & 12785 & 11788 \\
\hline 3 & - & + & - & - & 34895 & 25023 \\
\hline 4 & + & + & - & - & 25287 & 27771 \\
\hline 5 & - & - & + & - & 16593 & 19442 \\
\hline 6 & + & - & + & - & 10206 & 13296 \\
\hline 7 & - & + & + & - & 35123 & 25364 \\
\hline 8 & + & + & + & - & 38005 & 32103 \\
\hline 9 & - & - & - & + & 7479 & 7438 \\
\hline 10 & + & - & - & + & 3052 & 3171 \\
\hline 11 & - & + & - & + & 15527 & 16842 \\
\hline 12 & + & + & - & + & 11691 & 12256 \\
\hline 13 & - & - & + & + & 9179 & 9030 \\
\hline 14 & + & - & + & + & 5992 & 6237 \\
\hline 15 & - & + & + & + & 16916 & 15388 \\
\hline 16 & + & + & + & + & 20047 & 19181 \\
\hline
\end{tabular}

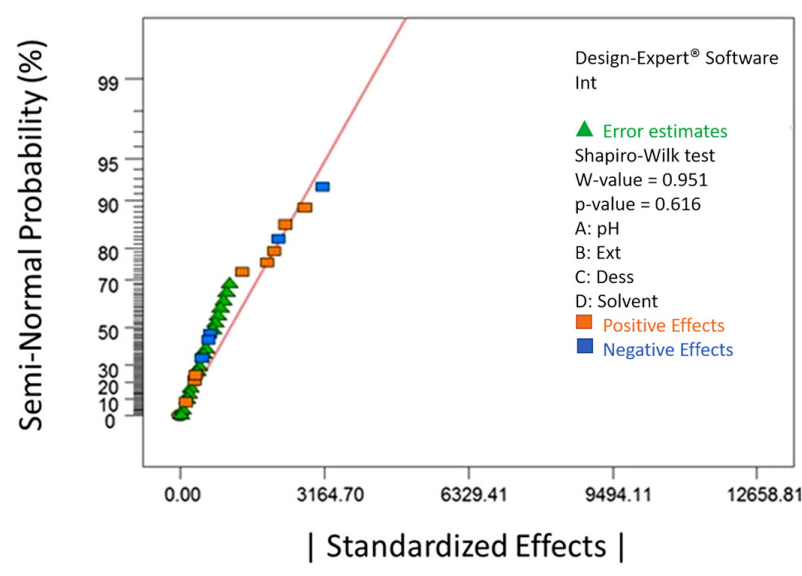

Figure 5. Graph of semi-normal distribution.

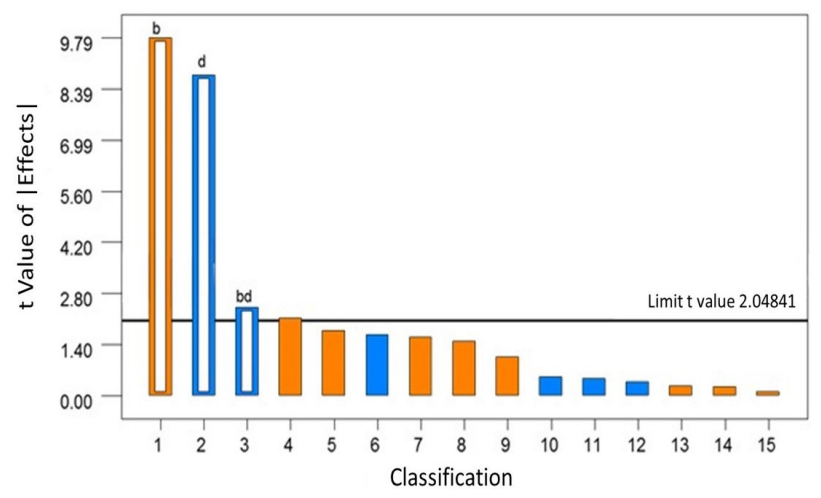

Figure 6. Pareto diagram obtained for the studied variables, where $b$ means the number of extraction cycles, $d$ means the solvent used to desorption, and bd means the interaction between $b$ and $d$ parameters. The colors orange and blue are attributed to positive and negative effects, respectively.

normal distribution: extraction cycles and desorption solvent. In the diagram it is also possible to observe that the interaction effect between these two variables is significant, there is influence between the variation of one over the other. However, as this interaction effect is very close to the boundary line, its influence on extractions is smaller than when analyzing each variable separately.

In order to statistically verify the variation of experimental responses produced by the significant variables to the factorial design model, the analysis of variance (ANOVA) was used and the results are presented in Table 5.

In this type of analysis, the $p$ values obtained equal or less than 0.05 are significant, since they show, with $95 \%$ confidence or more, that these parameters influence the extraction responses. The ANOVA, presented in Table 6, shows that the significant parameters in the Pareto diagram also have a $p$-value less than 0.05 .

ANOVA confirms that the two main effects in the extraction with DPX-RAM are the extraction cycle and the desorption solvent, since the confidence that these parameters influence in the analysis is greater than $99.9 \%$. As shown in the Pareto diagram, the interaction effect between these two variables is also significant, this is a secondary effect and the confidence of it influences the extraction experiments with DPX-RAM is $97.76 \%$.

The extraction efficiency using DPX is based on the equilibrium time of sorption between the sample solution and extraction phase. In this way, the result from the factorial design illustrates that the more extraction cycles are performed the higher is the intensity of the response, which is consistent with DPX mode of operation. Also, as the affinity between the desorption solvent and the analyte increases, there is an improvement in the desorption of 
Table 5. Analysis of variance (ANOVA) for the significant effects, where b means the number of extraction cycles, $d$ means the solvent used to desorption, and bd means the interaction between $b$ and $d$ parameters

\begin{tabular}{|c|c|c|c|c|c|}
\hline \multicolumn{6}{|c|}{ ANOVA for the factorial design } \\
\hline \multicolumn{6}{|c|}{ Analysis of variance (partial sum of squares-type III) } \\
\hline Source & Sum of squares & Df & Square mean & $F$ value & $\begin{array}{l}p \text { value } \\
\text { prob }>F\end{array}$ \\
\hline Model & $2.389 \times 10^{9}$ & 3 & $7.963 \times 10^{8}$ & 59.57 & $<0.0001$ \\
\hline $\mathrm{b}$ & $1.282 \times 10^{9}$ & 1 & $1.282 \times 10^{9}$ & 95.90 & $<0.0001$ \\
\hline $\mathrm{d}$ & $1.029 \times 10^{9}$ & 1 & $1.029 \times 10^{9}$ & 76.96 & $<0.0001$ \\
\hline bd & $7.813 \times 10^{7}$ & 1 & $7.813 \times 10^{7}$ & 5.84 & 0.0224 \\
\hline Residual & $3.743 \times 10^{8}$ & 28 & $1.337 \times 10^{7}$ & & \\
\hline Error & $1.451 \times 10^{8}$ & 16 & $9.067 \times 10^{6}$ & & \\
\hline $\begin{array}{c}\text { Total } \\
\end{array}$ & $2.763 \times 10^{9}$ & 311 & & & \\
\hline
\end{tabular}

the retained analyte from the extractive phase. Thus, the results found that the solvent desorption influences the response generated with the DPX-RAM extraction phase are consistent with the literature. ${ }^{19,28,29}$ Based on this, the optimum experimental conditions for the extractions of cocaine in oral fluid by DPX-RAM is 10 cycles of extraction (aspirate/dispense) and acetonitrile as desorption solvent, following the trend of the most significant effects. However, the other two variables do not present significant influence. Thus, it was chosen to carry out the extractions in $0.05 \mathrm{~mol} \mathrm{~L}^{-1}$ phosphate buffer solution of $\mathrm{pH} 9$, because this $\mathrm{pH}$ is close to $\mathrm{p} K_{\mathrm{a}}$ of cocaine, ensuring that it is in molecular form during the extraction procedure. And finally, 3 desorption cycles (aspirate/dispense) were chosen because it is less laborious condition.

\section{Analytical assays for DPX-RAM/LC-MS method}

\section{Linearity and linear range}

The linearity of the method was demonstrated by the analytical curve constructed with cocaine in a concentration ranging from 10 to $100 \mathrm{ng} \mathrm{mL}^{-1}$. The analytical curve was plotted using the absolute signal intensity of the mass spectrum for the most intense $\mathrm{m} / \mathrm{z}$ fragment of cocaine, thus ensuring that all analyzed signal comes from the fragmentation of cocaine, eliminating possible interferences in the analysis. The most common fragmentation profile of cocaine $(\mathrm{m} / \mathrm{z}, 304)$ is the loss of a benzoyl group, giving the most abundant fragment $(\mathrm{m} / \mathrm{z} 182)$, as shown in Figure $4 \mathrm{~b}$.

The linearity of the standardized DPX-RAM/LC-MS method was determined using oral fluid samples (blank) spiked with cocaine at the concentrations of 10, 20,30,40, $50,60,70,80,90$ and $100 \mathrm{ng} \mathrm{mL}^{-1}$ and each of these points were analyzed in replicates $(n=5)$. The evaluated range was linear with the square of the correlation coefficient greater than 0.999 (Table 6), and the coefficients of variation of the points of the analytical curve were lower than $15 \%$, following ANVISA's regulations. Aiming to test if the linear regression model used is true, the ANOVA variance test was performed, the data obtained are presented in Table 6. As the probability of the $F$ value is much lower than 0.05 , it can be stated that the model is indeed linear.

Limit of detection (LOD) and limit of quantitation (LOQ)

For the determination of LOD and LOQ, ten measurements of the blank sample were performed,

Table 6. Linear regression and ANOVA test for the DPX-RAM/LC-MS method with their respective limit of detection (LOD), and limit of quantitation (LOQ)

\begin{tabular}{|c|c|c|c|c|c|}
\hline Matrix & Analyte & $\begin{array}{l}\text { Linear regression } \\
\left(\text { LOQ: } 100 \mathrm{ng} \mathrm{mL}^{-1}\right)\end{array}$ & $\mathrm{R}^{2}$ & $\mathrm{LOD} /\left(\mathrm{ng} \mathrm{mL} \mathrm{L}^{-1}\right)$ & $\mathrm{LOQ} /\left(\mathrm{ng} \mathrm{mL}^{-1}\right)$ \\
\hline Oral fluid & cocaine & $y=84.276 x+1055.7$ & 0.9990 & 3.13 & 9.48 \\
\hline \multicolumn{6}{|c|}{ ANOVA test } \\
\hline & Df & Sum of squares & Square mean & $F$ value & Prob $>F$ \\
\hline Model & 1 & 13322.54403 & 13322.54403 & 46617.20892 & $2.220 \times 10^{-16}$ \\
\hline Error & 8 & 2.28629 & 0.28579 & & \\
\hline Total & 9 & 133424.83032 & & & \\
\hline
\end{tabular}

ANOVA: analysis of variance; LOD: limit of detection; LOQ: limit of quantification; Df: degrees of freedom; $\mathrm{R}^{2}$ : determination coefficient. 
specifically, oral fluid extracted by DPX-RAM without the presence of cocaine. Then, equations 2 and 3 were used to perform the calculations, as described below:

$\mathrm{LOD}=3 \times\left(\frac{\mathrm{STD}}{\alpha}\right)$

$\mathrm{LOQ}=10 \times\left(\frac{\mathrm{STD}}{\alpha}\right)$

where, STD is the standard deviation of 10 measurements of blank samples and $\alpha$ is the angular coefficient in the analytical curve.

The values empirically obtained were: $\mathrm{LOD}=3.13 \mathrm{ng} \mathrm{mL}^{-1}$ and $\mathrm{LOQ}=9.48 \mathrm{ng} \mathrm{mL}^{-1}$. The limit of quantitation was also determined experimentally by means of the lowest concentration of cocaine that was able to be fragmented with precision and accuracy. The experimental LOQ was found to be $10 \mathrm{ng} \mathrm{mL}^{-1}$.

\section{Precision, accuracy, recovery, and matrix effect}

In order to evaluate recovery (R), accuracy (E), intra and interday precision $(\mathrm{P})$, blank samples of oral fluid spiked with standard cocaine were prepared at three concentration levels: 10,50 , and $100 \mathrm{ng} \mathrm{mL}^{-1}$; for each concentration, the tests were performed in replicate $(n=5)$. Equations 4,5 and 6 , as described below, were used in the calculations, and the results can be seen in Table 7.

$\mathrm{R}(\%)=\frac{\mathrm{EC}}{\mathrm{TC}} \times 100$

$$
\begin{aligned}
& E(\%)=\left(\frac{C-T C}{T C}\right) \times 100 \\
& P(\%)=\left(\frac{S T D}{C}\right) \times 100
\end{aligned}
$$

where $\mathrm{EC}$ is the concentration determined experimentally, TC is the theoretical concentration, $\mathrm{C}$ is the average of experimental concentration and STD is the standard deviation between the concentrations.

The matrix effect was evaluated through the parallelism between the analytical and the calibration curve, and the intercept comparison. Both curves were built in replicate $(\mathrm{n}=5)$ at the concentration levels of 10, 20, 30, 40, 50, 60, $70,80,90$, and $100 \mathrm{ng} \mathrm{mL}^{-1}$, were the calibration curve was composed of standard cocaine in water, and the analytical curve was composed of saliva spiked with standard cocaine. A $t$-test was performed to compare both intercept and slopes at the 0.05 significance level (Table 8 ).

Since the $P$-value $(0.0001)$ in the equality of intercept test is lower than 0.05 , it is possible to conclude that the lines do not have the same intercept. Regarding the parallelism test, since the $P$-value ( 0$)$ is lower than 0.05 , it is possible to conclude that the lines are not parallel. In other words, the matrix effect is present in this methodology.

The evaluation of matrix effect, if it is considerable or not, can be assessed by comparing the slope of a calibration curve for standard solutions to the slope of a analytical curve matched standard solutions, ${ }^{40}$ or calculation of the recovery values in several points of a standard calibration curve by adding the standard solution to the real sample

\begin{tabular}{|c|c|c|c|c|}
\hline \multirow{2}{*}{ Concentration / $\left(\mathrm{ng} \mathrm{mL}^{-1}\right)$} & \multirow{2}{*}{ Accuracy / \% } & \multicolumn{2}{|c|}{ Precision / \% } & \multirow{2}{*}{ Recovery / \% } \\
\hline & & Intraday & Interday & \\
\hline 10.0 & 4.3 & 7.4 & 9.1 & 97.9 \\
\hline 50.0 & -0.9 & 2.1 & 2.5 & 100.1 \\
\hline 100.0 & 0.5 & 1.7 & 2.3 & 101.1 \\
\hline
\end{tabular}

Table 7. Precision, accuracy, and recovery for cocaine analysis in oral fluid by DPX-RAM/LC-MS method

Table 8. Intercept and slope comparison on $t$-test to evaluate matrix effect

\begin{tabular}{lcccc}
\hline & Estimation & Standard deviation & $t$ & $p$-value \\
\hline Intercept & 1055.7 & 651.4777 & 1.6205 & 0.1247 \\
Concentration & 84.276 & 10.4995 & 8.0267 & 0 \\
Calibration curve & -4567.9 & 921.3286 & -4.9579 & 0.0001 \\
Concentration:calibration curve & 431.2422 & 14.8486 & 29.0427 & 0 \\
\hline & Degree of freedom & Sum of squares & $F$ & 0.0001 \\
\hline Equality of the intercept & 1 & 22356118.2964 & 24.5813 & 0 \\
Parallelism & 1 & 767125504.9396 & 843.4787 & 0 \\
Coincidence & 2 & 2600818435.8216 & 1429.841 & \\
\hline
\end{tabular}


matrix. ${ }^{41}$ As can be seen in Tables 7 and 8 the recoveries values are high enough (98-101\%). Therefore, the response of the developed method cannot be affected by the sample matrix.

According to ANVISA, ${ }^{32}$ accuracy and precision values below $15 \%$ are desirable. Recovery values close to $100 \%$ are desirable, but values between 80 and $120 \%$ are also acceptable as long as recovery is precise and accurate. In the extraction process using DPX-RAM, the influence of proteins present in oral fluid was minimized due to the ability of the adsorbent phase to exclude such interferents. In this way, satisfactory analytical recovery rates were obtained.

In the literature, there are no reports of cocaine analysis with an extraction step done with RAM phases. However, Bordin et $a l .{ }^{42}$ used a commercial DPX tip containing an ion exchange adsorbent phase to analyze cocaine, nicotine and their metabolites in meconium samples by GC-MS with a derivatization step. The authors obtained recovery values for cocaine between 73 and $97 \%$. Thus, with the use of the RAM-BSA phase as the adsorbent phase for DPX and LCMS analysis, there is no need to perform a derivatization step in addition to an increase in cocaine recovery. ${ }^{42-44}$

Dulaurent et al. ${ }^{45}$ reported a methodology using quick, easy, cheap, effective, rugged, and safe (QuEChERS) as sample preparation technique for LC-MS/MS analysis of abuse drugs in whole blood. The sample preparation step was performed in $20 \mathrm{~min}$, and the authors reported $3 \mathrm{ng} \mathrm{mL}^{-1}$ as LOD. Ellefsen et al $^{46}$ reported the determination of cocaine and benzoylecgonine in saliva after controlled intravenous cocaine administration. The authors reported $1 \mathrm{ng} \mathrm{mL}{ }^{-1}$ as LOD. Melanson et al.$^{47}$ reported a LC-MS/MS

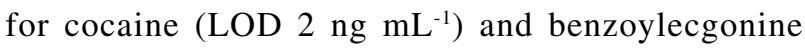
(LOD $5 \mathrm{ng} \mathrm{mL}^{-1}$ ). García-Valverde et al. ${ }^{48}$ modified cotton fibers with $\beta$-cyclodextrins and applied it as sorbent to cocaine and methamphetamine extraction in saliva samples. Bernardo et al ${ }^{13}$ reported the use of platinum wires coated with polypyrrole as needle for probe electrospray ionization, determining cocaine, lysergic acid diethylamide (LSD), methamphetamine and 3,4-methylenedioxymethamphetamine (MDMA) in oral fluid and urine samples. ${ }^{13}$

The methodology described here is sensitive, with LOD close to the ones reported in the literature ${ }^{46-48}\left(3 \mathrm{ng} \mathrm{mL}^{-1}\right)$. The DPX-RAM/LC-MS is also considered to be a fast technique, since the sample preparation took less than 5 min for each sample. The standardized and validated DPX-RAM/LC-MS method showed to be promising for drug determination in oral fluid and other drugs could be also analyzed.

\section{Conclusions}

In this work, a new method, DPX-RAM/LC-MS, for the analysis of cocaine in oral fluid was standardized and validated. The RAM-BSA phase used as an adsorbent in the DPX extraction, successfully excluded the interfering compounds in oral fluid, making method more selective for the analyte of interest.

According to the parameters of analytical validation, the proposed method is adequate, since its values of precision, accuracy, and recovery are within the standards established by ANVISA. The method also has a wide range of linearity and adequate $\mathrm{R}^{2}$, LOD and LOQ values. In addition to simplicity, low cost, low solvent consumption, speed, and efficiency.

The DPX-RAM/LC-MS method showed a good range of linearity and little matrix effect, evidenced by recovery and linearity values. The developed methodology showed to be a promising tool for routine forensic analysis.

\section{Acknowledgments}

This work was supported by grants from the Coordenação de Aperfeiçoamento de Pessoal de Nível Superior (CAPES), and Conselho Nacional de Desenvolvimento Científico e Tecnológico (CNPq). The whole team involved in this work thanks Prof Wanderson Romão and the Polícia Civil de Goiás, who kindly donated us the drugs standards. We also thank Prof Anselmo Elcana de Oliveira for contributing to the chemometric analysis, and Prof Raphaela de Castro Georg who kindly borrowed the necessary equipment for the Bradford test. We would also like to express our gratitude to Jennett Chenevert Aijala, who kindly helped in the revision process of this work.

\section{References}

1. Moreno-Artero, E.; Querol-Cisneros, E.; Rodríguez-Garijo, N.; Tomás-Velázquez, A.; Antoñanzas, J.; Secundino, F.; Pilar Gil-Sánchez, M.; España, A.; J. Eur. Acad. Dermatol. Venereol. 2018, 32, 1420.

2. Principles of Forensic Toxicology, $5^{\text {th }}$ ed.; Levine, B. S.; Kerrigan, S., eds.; Springer: Cham, Switzerland, 2020.

3. Dini, G.; Bragazzi, N. L.; Montecucco, A.; Rahmani, A.; Durando, P.; J. Prev. Med. Hyg. 2019, 60, E124.

4. Frederick, D. L.; Clin. Lab. Med. 2012, 32, 467.

5. Conselho Nacional de Trânsito (CONTRAN); Resolução No. 517 de 29 de janeiro de 2015, Altera a Resolução CONTRAN No. 425, de 27 de novembro de 2012, que dispõe sobre o Exame de Aptidão Física e Mental, a Avaliação Psicológica e o Credenciamento das Entidades Públicas e 
Privadas de que Tratam o art. 147, I e $\$ 1^{\circ}$ a $4^{\circ}$, e o art. 148 do Código de Trânsito Brasileiro; Diário Oficial da União (DOU), Brasília, No. 21, de 30/01/2015, p. 110, available at https:// www.in.gov.br/materia/-/asset_publisher/Kujrw0TZC2Mb/ content/id/32139290/do1-2015-01-30-resolucao-n-517-de-29de-janeiro-de-2015-32139229, accessed in August 2021.

6. Moeller, M. R.; Steinmeyer, S.; Kraemer, T.; J. Chromatogr. B: Biomed. Sci. Appl. 1998, 713, 91.

7. Dinis-Oliveira, R. J.; Toxicol. Mech. Methods 2015, 25, 494.

8. Toyo'oka, T.; Biol. Pharm. Bull. 2016, 39, 1397.

9. Vasconcelos, I.; Fernandes, C.; TrAC, Trends Anal. Chem. 2017, $89,41$.

10. Wudy, S. A.; Schuler, G.; Sánchez-Guijo, A.; Hartmann, M. F.; J. Steroid Biochem. Mol. Biol. 2018, 179, 88.

11. Lísa, M.; Cífková, E.; Khalikova, M.; Ovčačíková, M.; Holčapek, M.; J. Chromatogr. A 2017, 1525, 96.

12. Drouin, N.; Rudaz, S.; Schappler, J.; J. Pharm. Biomed. Anal. 2018, 159, 53.

13. Bernardo, R. A.; da Silva, L. C.; Queiroz, M. E. C.; Vaz, B. G.; Chaves, A. R.; J. Chromatogr. A 2019, 1603, 23.

14. Telepchak, M. J.; August, T. F.; Chaney, G.; Forensic and Clinical Applications of Solid Phase Extraction; Humana Press: Totowa, New Jersey, USA, 2004.

15. Soriano, T.; Jurado, C.; Menéndez, M.; Repetto, M.; J. Anal. Toxicol. 2001, 25, 137.

16. Logan, B. K.; Stafford, D. T.; Tebbett, I. R.; Moore, C. M.; J. Anal. Toxicol. 1990, 14, 154.

17. Franke, J. P.; de Zeeuw, R. A.; J. Chromatogr. B: Biomed. Sci. Appl. 1998, 713, 51.

18. Hennion, M.-C.; J. Chromatogr. A 1999, 856, 3.

19. Chaves, A. R.; Moura, B. H. F.; Caris, J. A.; Rabelo, D.; Queiroz, M. E. C.; J. Chromatogr. A 2015, 1399, 1.

20. Fernandes, A. R.; de Souza, P. S.; de Oliveira, A. E.; Chaves, A. R.; J. Braz. Chem. Soc. 2018, 29, 695.

21. Lehotay, S. J.; Mastovska, K.; Lightfield, A. R.; Nuñez, A.; Dutko, T.; Ng, C.; Bluhm, L.; J. Chromatogr. A 2013, 1313, 103.

22. Pinto, M. A. L.; Queiroz, M. E. C.; Sci. Chromatogr. 2015, 7, 101.

23. Bordin, D. C. M.; Alves, M. N. R.; de Campos, E. G.; de Martinis, B. S.; J. Sep. Sci. 2016, 39, 1168.

24. Miyazaki, S.; Morisato, K.; Ishizuka, N.; Minakuchi, H.; Shintani, Y.; Furuno, M.; Nakanishi, K.; J. Chromatogr. A 2004, 1043, 19.

25. Ota, S.; Miyazaki, S.; Matsuoka, H.; Morisato, K.; Shintani, Y.; Nakanishi, K.; J. Biochem. Biophys. Methods 2007, 70, 57.

26. Hsieh, H.-C.; Sheu, C.; Shi, F.-K.; Li, D.-T.; J. Chromatogr. A 2007, 1165, 128.

27. Mafra, G.; Spudeit, D.; Brognoli, R.; Merib, J.; Carasek, E.; J. Chromatogr. B 2018, 1102-1103, 159.

28. Desilets, C. P.; Rounds, M. A.; Regnier, F. E.; J. Chromatogr. A 1991, 544, 25.
29. de la Guardia, M.; Esteve-Turrillas, F. A.; Handbook of Smart Materials in Analytical Chemistry, vol. I, $1^{\text {st }}$ ed.; de la Guardia, M.; Esteve-Turrillas, F. A., eds.; Wiley: Chichester, West Sussex, UK, 2019.

30. Alshali, R. Z.; Salim, N. A.; Satterthwaite, J. D.; Silikas, N.; J. Dent. 2015, 43, 1511.

31. Bradford, M. M.; Anal. Biochem. 1976, 72, 248.

32. Agência Nacional de Vigilância Sanitária (ANVISA); Resolução da Diretoria Colegiada (RD) No. 166, de 24 de julho de 2017, Dispõe sobre A Validação de Métodos Analíticos e dá Outras Providências; Diário Oficial da União (DOU), Brasília, No. 141 , de 25/07/2017, p. 87 , available at https://www. in.gov.br/materia/-/asset_publisher/Kujrw0TZC2Mb/content/ id/19194581/do1-2017-07-25-resolucao-rdc-n-166-de-24-dejulho-de-2017-19194412, accessed in August 2021.

33. de Lima, V. V.; Cassiano, N. M.; Cass, Q. B.; Quim. Nova 2006, 29,72 .

34. D’Avila, F. B.; Pereira, A. G.; Salazar, F. R.; Ferreira, P. L.; Salazar, C. R.; Limberger, R. P.; Fröehlich, P. E.; J. Pharm. Biomed. Anal. 2015, 103, 67.

35. Paulsen, R. B.; Wilkins, D. G.; Slawson, M. H.; Shaw, K.; Rollins, D. E.; J. Anal. Toxicol. 2001, 25, 490.

36. Pereira, A. G.; D’Avila, F. B.; Ferreira, P. C. L.; Holler, M. G.; Limberguer, R. P.; Froehlich, P. E.; Chromatographia 2016, 79, 179.

37. Pereira, A. G.; D’Avila, F. B.; Ferreira, P. C. L.; Holler, M. G.; Limberger, R. P.; Fröehlich, P. E.; Anal. Methods 2014, 6, 456.

38. Scheidweiler, K. B.; Huestis, M. A.; Anal. Chem. 2004, 76, 4358.

39. Design-Expert, version 13; Stat-Ease, Inc., USA, 2021.

40. Zhou, W.; Yang, S.; Wang, P. G.; Bioanalysis 2017, 9, 1839.

41. Steiner, D.; Krska, R.; Malachová, A.; Taschl, I.; Sulyok, M.; J. Agric. Food Chem. 2020, 68, 3868.

42. Bordin, D. C. M.; Alves, M. N. R.; Cabrices, O. G.; de Campos, E. G.; de Martinis, B. S.; J. Anal. Toxicol. 2014, 38, 31.

43. Montesano, C.; Simeoni, M. C.; Curini, R.; Sergi, M.; lo Sterzo, C.; Compagnone, D.; Anal. Bioanal. Chem. 2015, 407, 3647.

44. Fernández, P.; Morales, L.; Vázquez, C.; Lago, M.; Bermejo, A. M.; J. Appl. Toxicol. 2008, 28, 998.

45. Dulaurent, S.; El Balkhi, S.; Poncelet, L.; Gaulier, J. M.; Marquet, P.; Saint-Marcoux, F.; Anal. Bioanal. Chem. 2016, 408, 1467.

46. Ellefsen, K. N.; Concheiro, M.; Pirard, S.; Gorelick, D. A.; Huestis, M. A.; Forensic Sci. Int. 2016, 260, 95.

47. Melanson, S. E. F.; Petrides, A. K.; Khaliq, T.; Griggs, D. A.; Flood, J. G.; J. Appl. Lab. Med. 2020, 5, 935.

48. García-Valverde, M. T.; Soriano, M. L.; Lucena, R.; Cárdenas, S.; Anal. Chim. Acta 2020, 1126, 133.

Submitted: May 6, 2021

Published online: August 11, 2021 